\title{
Influence of leucosapphire tubes growing conditions on strength of insulators made of the tubes
}

\author{
V.I.Vybyvanets, N.A.Bochkov, S.A.Konarev, \\ D.Ya.Kravetsky, V.A.Sokolov, D.L.Tsetskhladze
}

\author{
Federal State Unitarian Enterprise "Scientific Research Institute \\ Scientific Industrial Association "LUCH", 24 Zheleznodorozhnaya St., \\ 142100 Podolsk, Moscow region, Russian Federation
}

\author{
Received February 1, 2013
}

\begin{abstract}
The influence of leucosapphire tubes growing conditions (grades of molybdenum used for form-builders; raw materials brands; rates of growing; designs of form-builders and a growing tube shielding) on strength of the insulators made of the tubes have been studied.
\end{abstract}

\begin{abstract}
Изучено влияние условий выращивания трубок из лейкосапфиру (марки молибдена, из которого изготавливаются формообразователи; марки исходного сырья; скорости выращивания; конструкции экранировки формообразователя и растущей трубы) на прочность изготовленных из них изоляторов.
\end{abstract}

Вплив умов вирощування трубок з лейкосапфіра на міцність виготовлених з них ізоляторів. В.І.Вибиванець, Н.О.Бочков, С.О.Конарєв, Д.Я.Кравецький, В.О.Соколов, Д.л.Цецхладзе.

Вивчено вплив умов вирощування трубок з лейкосапфіра (марки молібдену, з якого виготовляються формообразователі; марки вихідної сировини; швидкості вирощування; конструкції екранировки формоутворювачем і зростаючої труби) на міцність виготовлених з них ізоляторів.

\section{Introduction}

One of the basic constructive elements of modern electric vacuum devices is a metalceramic unit consisting of a ceramic insulator and two metal cuffs, compatible by factors of thermal expansion. A metal-ceramic unit (MCU) usually operates under extreme conditions and it is exposed to repeated thermocyclic loadings. Application of leucosapphire as an insulator material is an important reserve of increase in the MCU reliability.

As it is known, leucosapphire crystals strength is defined by their structure, presence of pores (bubbles) and impurities, residual stresses; and strength and thermal stability of the products made of leucosapphire also depend on grade and quality of mechanical-diamond treatment and elimination of the stresses occurring at the treatment. In spite of the fact that profiled leucosapphire single crystals have successfully been grown for more than 30 years, a problem on crystallization conditions influence on mechanical properties of the profiled leucosapphire has been studied insufficiently, and the obtained results have a fragmentary nature.

In [1] a growing atmosphere influence on a dislocation structure, pores density and distribution, and also the profiled leucosapphire crack resistance was studied concerning the tubes of $40 \mathrm{~mm}$ in a diameter. 
The article [2] shows an ultimate strength dependence on the grown crystal length using leucosapphire samples grown as rods of $3 \times 3 \mathrm{~mm}^{2}$ in cross-section. It was found out that the strength was reduced by the crystal length due to blockiness development, and it is a rather clear conclusion.

The results of investigations into leucosapphire application for fabrication of pressuring assemblies are given in [3] and [4]:

- The obtained dependence of the flexural ultimate strength of samples-small bars made of leucosapphire of $3 \mathrm{~mm}$ in diameter and $20 \mathrm{~mm}$ in length on a growing rate indicates that the growing rate has a considerable effect on the crystals strength.

- Leucosapphire strength (samples-small bars) is by (2-2.5 times) more than strength of polycrystal sintered aluminum oxide in the temperatures range of $20^{\circ} \mathrm{C}$ up to $1700^{\circ} \mathrm{C}$.

Based on the analysis of the references we can make a conclusion that the data obtained at the investigations into the profiled leucosapphire crystals strength cannot be applied directly for this paper theme since the strength of the samples as rods or small bars was studied. Practically there are no investigations of dependence of the insulators themselves on conditions and modes of profiled leucosapphire crystals growth.

The following problems were set in this paper:

- direct investigations in the insulators strength in dependence on parameters of the tubes - blanks which were used for these insulators fabrication;

- specifying of the technological tubes parameters which are the most important by their influence on the insulators strength;

- the tubes with the outer diameter of $16.6 \mathrm{~mm}$, inner diameter of $7.5 \mathrm{~mm}$ and length of $150 \mathrm{~mm}$ were grown under Stepanov method for fabrication of the insulators with an outer diameter of 14.5_ $0.1 \mathrm{~mm}$, inner diameter of $9.5_{+0.1} \mathrm{~mm}$, and length of $15_{-0.1} \mathrm{~mm}$. The tubes were grown using a specialized plant of SZVN with a resistive heating and a graphite thermal zone.

Rod seed crystals with a crystallographic orientation [0001] $\pm 1^{\circ}$ were used for reducing in the deviation of a geometric tube axis from a crystallographic direction [0001] and for reducing in disorientation in the tube blockiness occurring in the process of growing. The seed crystals were made of leucosapphire crystals grown under Kiropulos method.
Obtaining of the given tubes sizes was provided by the mode stabilization, for example, the outer tube diameter was grown with accuracy of $-0.3 \mathrm{~mm}$.

A process of the tubes fabrication from the insulators included the following consecutive operation:

- Tubes annealing in vacuum at a temperature of $1850^{\circ} \mathrm{C}$ for $4 \mathrm{~h}$;

- Cutting of the areas of the tube proliferation and tearing; grinding and polishing of the tube ends with the following control and rejection;

- Marking and cutting into the blanks with a length of $18 \mathrm{~mm}$;

- Diamond polishing of the insulators blanks;

- Control of the fabricated insulators;

- Annealing of the conditioned insulators under the same mode that was used at the tubes annealing (refer to abovementioned);

- After the final control the insulators are sent to the direct strength testing.

For the purpose of investigation of an influence of the parameters and conditions of the tubes-blanks growth on the insulators strength, the special measures were taken in order that mechanical diamond treatment to be maximally identical both from batch to batch, and from insulator to insulator; the treatment quality was carefully controlled; the modes and the treatment operations sequence were strictly observed; the treatment was made until a roughness value reached $R_{z}=0.04$.

Proceeding from experience of FSUE "SRI SIA "LUCH" on growing of the tubes made of leucosapphire for insulators fabrication, the following parameters were selected as basic parameters of growing which had influence on the insulators strength:

- Brand of molybdenum from which form-builders (final devices for obtaining of leucosapphire profiles as tubes) are made;

- Initial raw material brand;

- Growing rate;

- Form-builder shielding and growing tube designs.

Besides the mentioned parameters, the other technological parameters of leucosapphire tubes growing are available such as brand of thermal zone graphite; brand of argon in which atmosphere the tubes are grown; modes of the obtained tubes annealing; design of working edges of a formbuilder, and also other parameters less essential in our opinion, but due to high labor-intensiveness of the investigations 
carried out, study of these parameters was not planned in this paper.

Substantiations for selection of the basic abovementioned parameters to be studied are given thereinafter.

Molybdenum used for fabrication of the form-builders and a crucible is in a constant contact with aluminum oxide melt at a temperature above $2054^{\circ} \mathrm{C}$ (melting temperature of aluminum oxide). The molybdenum and impurities contained in it make the melt dirty, and then when getting to the crystal, they break a crystal lattice and promote increase in blocks formation of the growing tubes that leads to decrease in strength.

The initial raw material of aluminum oxide also contains impurities which can reduce strength and thermal stability [5] due to increased amount of pores and the crystal structure breakage. Increase in the growing rate more than the certain limit leads to increase in capture of the impurities and pores from the melt, increase in blocks formation that also reduces the strength. A design of the form-builder shielding and growing tube defines the residual stresses and blocks amount in it, and it has a direct effect on the strength and thermal stability.

During every process of the tubes growing one crystallization parameter was varied while the other parameters remained constant. For all of the growing variants the following parameters were constant: a crucible, argon pressure, conditions of seeding and tubes proliferation, modes of heating and raw materials melting.

\section{Investigations results}

Strength of the fabricated insulators at loading by an internal pressure was chosen as a criterion of the grown tubes quality. A set of rubber bushings placed within the insulator was used as a working medium transferring pressure from the testing device to the internal insulator surface. In this case a deformation mode is realized in the insulator, which is similar to the tension oriented perpendicularly to the insulator axis.

The strength value was calculated by equation [6]:

$$
\sigma=P\left(R^{2}+r^{2}\right) /\left(R^{2-}-r^{2}\right),
$$

where $R$ and $r$ are outer and inner insulator radiuses, $P$ is a destroying internal pressure in the insulator.

A device for the insulators testing under loading by the internal pressure is shown

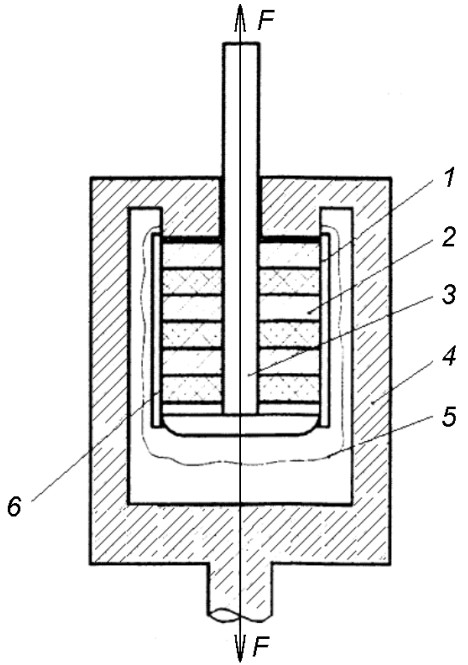

Fig. 1. Scheme of a device for the mechanical strength tubes testing under loading by internal pressure: 1 - a tube (insulator), 2 rubber bushings, 3 and $4-$ puncheons, $5-$ a polyethylene bag, 6 - a gasket.

schematically in Fig. 1. The internal pressure is realized by an axial compression of the rubber bushings set which is tightly inserted into insulator 1 . The compression is made by two puncheons forming a reverser. One of them is rod-shaped 3. Prior to the device assembling, the rubber bushings, gaskets 6 and the tested insulator are put on it in sequence. The second puncheon 4 is made as a shell ring in which the first puncheon is placed in the completed form. Prior the tests, a gap between the rubber bushings set and internal insulator surface is removed by pressing a special nut (not shown in the figure). Then the puncheons are fixed in gripping devices of the universal testing machine 1958-U-2. The device was loading with a rate of $10 \mathrm{~kg} / \mathrm{s}$ after setting " 0 " of the loading gauges and the testing machine deformation. For gathering of the destroyed insulation pieces after the tests, the latter was put into a polyethylene.

A strength measurement error was $1 \%$.

The following variants of growth were studied.

1) Molybdenum brand: a) $\mathrm{MCH}$ (pure molybdenum);

b) MCHVP (pure molybdenum after vacuum melting);

c) Single crystal (was grown at FSUE "SRI SIA "LUCH").

In accordance with data of a certification organization - Ancerteko, LLC - the least content of impurities was in the molybdenum single crystal, the most was in molybdenum of a $\mathrm{MCH}$ brand. 
Table 1. Influence of form-builder material brand on insulators strength

\begin{tabular}{|c|c|c|c|c||}
\hline \hline $\begin{array}{c}\text { Form-builder material } \\
\text { brand }\end{array}$ & $\begin{array}{c}\text { MCHVP, } \\
\text { batches 4 and 5 }\end{array}$ & $\begin{array}{c}\text { MCHVP, } \\
\text { all batches }\end{array}$ & $\begin{array}{c}\text { Single crystal, } \\
\text { batches 6 and } 7\end{array}$ & $\begin{array}{c}\text { MCH, } \\
\text { batches } 1\end{array}$ \\
\hline$\sigma, \mathrm{MPa}$ & $422 \pm 36$ & $358 \pm 48$ & $395 \pm 46$ & $476 \pm 19$ \\
\hline
\end{tabular}

2) Initial raw material brand: a) SPEK (Ametist, LLC, Russia);

b) Non-standard (Chezh Republic);

c) RCA (France);

d) Pressed and sintered powder pellets (China)

e) HDPA (balls of $0.2 \mathrm{~mm}$ in a diameter), USA.

The least content of impurities (according to the data of certification organization - Ancerteko, LLC, Moscow) was in the Non-standard raw materials, then in the pressed pellets, RCA, SPEK and HDPA ((balls of $0.2 \mathrm{~mm}$ in a diameter).

3) A rate of growing, $\mathrm{mm} / \mathrm{min}: 0.5 ; 0.8$; 1.0; and 1.2 (RCA raw materials); $0.5 ; 1.0$ (SPEK raw materials).

4) A shielding design: a) A vertical cylindrical shield;

b) 2 vertical cylindrical shields.

The tests results under a "standard mode" were used as basis ones for comparison in influence of growing process parameters on the insulators strength: the molybdenum brand of a form-builder - MCHVP, initial raw material - RCA, growing rate $-0.8 \mathrm{~mm} / \mathrm{min}$, shields number -2 .

Not less than 3 processes of the tubes growing were conducted under every variant of the conditions; and 15-18 insulators were fabricated in total.

The results of the study of influence of the form-builder material brand on the insulators strength are given in Table 1.

The insulators from batches 1 and 2 (the form-builder was made of molybdenum of MCH brand, RCA raw material) showed a maximal strength value - $476 \mathrm{MPa}$ - according to the statistical Student's criterion. Also one can make a conclusion that application of molybdenum of $\mathrm{MCH}$ and MCHVP brands gives very similar results.

Probably, impurities or one of them contained in molybdenum of $\mathrm{MCH}$ brand and entering a growing tube during a crystallization process lead to occurrence of a residual stresses field (not completely removed at annealing) in the tube, which provides increase in strength under the internal pressure. This fact does not mean that such a phenomenon will remain at other kinds of the deformation mode.

Application of the molybdenum single crystal - the purest of all the used molybdenum brands - does not lead to increase in the strength. It indirectly indicates that impurities getting the melt from the formbuilder do not have an appreciable influence on the insulators strength and even can increase it (within the range of the batches studied). Probably, aluminum oxide melt can be doped with a certain impurity.

The results of the study in influence of an initial raw material brand on insulators strength are given in Table 2 .

The influence of the initial raw material brand on the insulators strength are mainly determined by a chemical composition of the raw materials and impurities getting to the product (tube) from the melt. As a whole, the impurities influence on strength of the insulators made of leucosapphire is not definite. They can lead both to reduction in the strength and its increase in dependence on a dissolution type (substation or penetration into the $\mathrm{Al}_{2} \mathrm{O}_{3}$ lattice), a relation of an impurity atom size and $\mathrm{Al}_{2} \mathrm{O}_{3}$ interatomic distance, impurity concentration, etc.

The obtained results show that both the purest raw material (Non-standard) and the

Table 2. Influence of raw material brand on insulators strength

\begin{tabular}{|c|c|c|c|c|c||}
\hline $\begin{array}{c}\text { Initial raw mate- } \\
\text { rial brand, } \mathrm{Al}_{2} \mathrm{O}_{3}\end{array}$ & SPEK & Non-standard & RCA & Pressed pellets & $\begin{array}{c}\text { HPDA, (balls } \\
\text { of 0.2 mm in } \\
\text { diameter) }\end{array}$ \\
\hline$\sigma, \mathrm{MPa}$ & $378 \pm 21$ & $337 \pm 42$ & $390 \pm 28$ & $348 \pm 38$ & $261 \pm 11$ \\
\hline
\end{tabular}

Table 3. Influence of growing crystals rate on insulators strength

\begin{tabular}{|c|c|c|c|c||}
\hline $\begin{array}{c}\text { Rate of grow- } \\
\text { ing, } \mathrm{mm} / \mathrm{min}\end{array}$ & 0.5 & 0.8 & 1.0 & 1.2 \\
\hline$\sigma, \mathrm{MPa}$ & $371 \pm 25$ & $379 \pm 21$ & $343 \pm 44$ & $317 \pm 17$ \\
\hline
\end{tabular}


Table 4. Influence of form-builders shields number on insulators strength

\begin{tabular}{|c|c|c||}
\hline \hline Shields number & 1 & 2 \\
\hline$\sigma, \mathrm{MPa}$ & $342 \pm 44$ & $380 \pm 21$ \\
\hline
\end{tabular}

"dirtiest" (balls of $0.2 \mathrm{~mm}$ in diameter) have the lowest value of strength, and the raw material with an average content of impurities (RCA and SPEK) gives the maximal value of the insulators strength. Therefore a conclusion on a possibility of the growing tubes doping can be made for increasing their strength.

Study of influence of specific kinds of impurities, for example $\mathrm{Ti}, \mathrm{Si}, \mathrm{Fe}$, etc on the strength is sure of interest, however, this task was not set in the paper due to a large volume of investigations. Such work is planned to be done in the future. The results of study on influence of the growing crystals rate on the insulators strength are given in Table 3.

The influence of the growing rate on the insulators strength are mainly determined by a possibility of the impurities capture from the melt, and also by a level of the residual stresses occurring within the crystal at crystallization. Since at the profiled crystals growing the impurities capture is a constant value within the range of the growing rates used by us, the residual stresses play the main role: the more growing rate the more level of the residual stresses. It can be seen from the Table that an optimal growing rate is 0.5$0.8 \mathrm{~mm} / \mathrm{min}$. It should be noted that there is the specific optimal growing rate for every individual product.

Influence of the form-builders shields number on the insulators strength is shown in Table 4.

The form-builders shields number affects the insulators strength due to dependence of the crystal quality (namely, a tube) on uniformity of the temperature field at its crystallization.

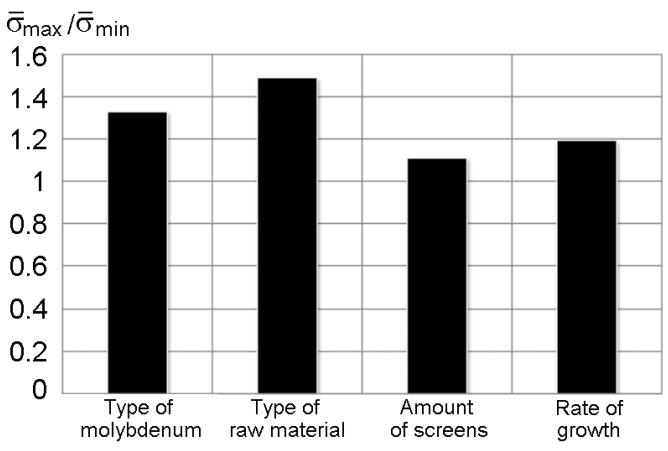

Fig. 2. Influence of technological parameters of growing leucosapphire tubes on insulators strength.

As it was supposed, increase in the temperature field uniformity and reductions in temperature gradients at application of 2 shields provide increase in the insulators strength.

In the studied range of the technological parameters of growing leucosapphire tubes the basic factors influencing the strength value are quality of the initial raw materials and the brand of molybdenum which the form-builder is made of (refer to Fig. 2 and Table 5), where $\sigma_{\max }$ and $\sigma_{\min }$ are the maximal and minimal average strength values of the batches of the insulators grown under the stated conditions, for example, from HPDA and RCA raw materials, in this case all the rest conditions were "standard", relation $\sigma_{\max } / \sigma_{\min }$ shows how variation of the given growing conditions influences the strength variation.

\section{Conclusion}

The strength of leucosapphire tube insulators was studied in dependence on the technological parameters of growth of the tubes which they are made of. It was ascertained that brands of the initial raw materials and molybdenum used for the formbuilders fabrication had a determining influence on the insulators strength.

Table 5. Summary table for estimation of influence of technological parameters of growing leucosapphire tubes on insulators strength

\begin{tabular}{|c|c|c|c||}
\hline Parameter & $\sigma_{\min }, \mathrm{MPa}$ & $\sigma_{\max }, \mathrm{MPa}$ & $\sigma_{\max } / \sigma_{\min }$ \\
\hline Brand of molybdenum for form-builder & $358(\mathrm{MCHVP}$, all batches) & $476(\mathrm{MCH})$ & 1.33 \\
Brand of initial raw material & 261 (HPDA) & $390(\mathrm{RCA})$ & 1.49 \\
Shields number & $342(1)$ & $380(2)$ & 1.11 \\
Growing rate, $\mathrm{mm} / \mathrm{min}$ & $317(1.2)$ & $379(0.8)$ & 1.19 \\
\hline
\end{tabular}


The obtained data on the optimal technological growth parameters were used at growing tubes for insulators fabrication.

\section{References}

1. E.P.Andreev, E.R.Dodrovinskaya, I.F.Zvyagintseva, et al., Izvestiaya Academy Sciences USSR. Phys. Ser., 47, 382 (1983).

2. M.Ya.Starostin, T.N.Yalovets, A.Zh.Rozenflants, V.A.Borodin, Izvestiaya Academy Sciences USSR. Phys. Ser., 58, 57 (1994).

3. A.P.Belousenko, Yu.I.Shapovalov, V.P.Kornilov et al., in: Proc. of All-USSR Meeting on
Obtaining of Profiled Crystals and Products by Stepanov's Method and their Application in the National Economy, PTI after Ioffe of AS of USSR, Leningrad (1986), p.128.

4. A.P.Belousenko, V.P.Kornilov, Yu.I.Shapovalov et al., Izvestiaya Academy Sciences USSR. Phys. Ser., 52, 1988 (1988).

5. L.M.Zatulovsky, B.B.Pelts, I.E.Beresina et al., Izvestiaya Academy Sciences USSR. Phys. Ser., 4.9, 2393 (1985).

6. Strength, Stability, Vibrations, Reference book by I.A. Birger and Ya.G.Panovko, Mashinostroenie, Moscow (1968) [in Russian]. 